\title{
La polisemia léxica y sus conexiones con algunas líneas de la interrelación entre léxico y sintaxis*
}

Lexical polysemy and the lexicon-syntax
interface

\author{
MARÍA DOLORES MUÑOZ NúÑEZ \\ Grupo de investigación "Semaínein" \\ Instituto Universitario de Investigación en Lingüística Aplicada \\ Departamento de Filología \\ Facultad de Filosofía y Letras \\ Universidad de Cádiz \\ Avda. Gómez Ulla, nº 1 \\ 11003 Cádiz-España \\ mdolores.munioz@uca.es
}

RECIBIDO: 18 DE JULIO DE 2016

Resumen: En este trabajo partimos de la controvertida distinción entre variantes e invariantes de contenido -en el marco del estructuralismo funcional europeo-, distinción no resuelta en muchos casos en los análisis sobre el fenómeno de la polisemia léxica, para conectar esta problemática, en el ámbito de la interrelación entre léxico y sintaxis, con el análisis: 1) de ciertas construcciones con el verbo hacer para comprobar si se ha producido o no una recategorización de este verbo y 2) de ciertas pruebas de comportamiento sintáctico-semántico con verbos de estado y de logro que nos conducirían a la posibilidad de que también aceptaran otras lecturas. En ambos tipos de estudios la pregunta esencial que habría que resolver no es, pues, la de si estamos ante variantes o invariantes de contenido, aunque el fenómeno de la polisemia léxica siempre está presente. Partiendo de los presupuestos teóricos del estructuralismo funcional europeo, incorporaremos otros de semántica composicional y de algunas orientaciones cognitivistas.

Palabras clave: Polisemia léxica. Verbo soporte. Recategorización. Subclase aspectual de los estados. Subclase aspectual de los logros.

* Esta contribución se inserta en el proyecto "Comunicación especializada y terminografía: usos terminológicos relacionados con los contenidos y perspectivas actuales de la semántica léxica" (FFI2014-54609-P), dirigido por el Prof. Dr. Miguel Casas Gómez y financiado por el Ministerio de Economía y Competitividad (Programa Estatal de Fomento de la Investigación Científica y Técnica de Excelencia. Subprograma Estatal de Generación del Conocimiento). 
Abstract: In this paper we start from the controversial distinction between variants and invariants of content -in the framework of the European functional structuralism-, distinction unresolved in many cases in the analysis of the phenomenon of lexical polysemy, to connect this problem, in the field of the interrelationship between lexicon and syntax, with the analysis: 1) of certain constructions with the verb do to check if it has not produced or re-categorization of this verb and 2) of certain tests syntactic-semantic behavior with verbs of state and achievement that would lead us to the possibility that also accept other readings. In both types of studies the essential question to be solved is not, then, whether we are dealing variants or invariants of content, although the phenomenon of lexical polysemy is always present. Based on the theoretical assumptions of the European functional structuralism, we incorporate other of the compositional semantics and some cognitivists orientations.

Keywords: Lexical polysemy. Verb support. Recategorization. Aspectual subclass of states. Aspectual subclass of achievement.

\section{INTRODUCCIÓN}

n octubre de 1996 defendimos en la Universidad de Cádiz nuestra tesis doctoral titulada La polisemia léxica. Propuesta de delimitación e identificación funcional de los significados de sustantivos polisémicos. El objetivo era redefinir el concepto de polisemia léxica en el marco de las relaciones léxicas, donde frecuentemente se había situado a este fenómeno, ${ }^{1}$ fijar los criterios para delimitar lo más claramente posible entre invariantes y variantes de contenido y establecer las bases para la elaboración de un diccionario funcional (teniendo en cuenta que el modelo teórico en el que mayoritariamente estaba insertada la tesis, más allá de la revisión historiográfica realizada, era el estructuralismo funcional europeo).

De nuestros estudios sobre el fenómeno de la polisemia léxica son de destacar, no sólo los resultados a los que en su momento llegamos, y que serán objeto de balance en esta contribución, sino la toma de conciencia, después de casi veinte años de defendida nuestra tesis, de las repercusiones de este fenómeno en distintos ámbitos de la Semántica y de sus conexiones con algunas líneas sobre las que en la actualidad estamos trabajando, como son la delimitación de los conceptos de colocación -frente al de restricción léxica- y de locución en algunos casos particulares, por una parte, y el análisis de ciertas supuestas constricciones sintáctico-semánticas de la aspectualidad en español, en el marco de la proyección del léxico en la sintaxis, por otra. En relación con estas investigaciones, pueden confrontarse algunos resultados parciales

1. Ver, en este sentido, el artículo de Casas Gómez y Muñoz Núñez (1992, 134-58), ampliamente citado en los estudios de semántica léxica, y, sobre todo, el libro derivado de la tesis mencionada (Muñoz Núñez 1999). 
publicados en diferentes artículos (ver, en concreto, Muñoz Núñez 2007, 2010a y 2010b).

En este trabajo pretendemos, pues, en una primera parte, hacer un balance, como adelantamos, de los resultados de una investigación de hace exactamente 19 años, incidiendo tanto en los objetivos cumplidos como en los problemas que todavía siguen presentándose cuando abordamos el fenómeno de la polisemia léxica, sobre todo en relación con la controvertida distinción entre variantes e invariantes de contenido y su vinculación con los planos del babla y de la lengua respectivamente. Derivado de lo anterior, valoraremos también el objetivo que en su momento nos planteamos sobre la posibilidad de elaborar un diccionario funcional.

En una segunda parte, desarrollaremos algunas propuestas en las que estamos trabajando en la actualidad y en cuyos análisis ocupa también un papel importante el fenómeno de la polisemia léxica. En este sentido, y en el estado actual de los estudios en Semántica léxica, consideramos que es desde la proyección del léxico en la sintaxis como mejor se puede abordar la conformación del significado léxico.

En esta línea de interrelación entre léxico y sintaxis, el primer aspecto -dentro de esta segunda parte- que abordaremos será el de la delimitación entre colocaciones y locuciones. Aunque todavía hay muchos problemas (más bien en lo referente a una puesta en común) en relación con la delimitación entre restricciones léxicas y colocaciones, estamos especialmente interesados en la formación de ciertas construcciones, en concreto con el verbo bacer (bacer cuentas, hacer el payaso, hacer una barriga, hacer una montaña de un grano de arena, hacer un siete), en comparación con dar, sobre las que cabría preguntarse: 1) ¿estamos en estos casos ante una gramaticalización donde hacer se ha convertido en verbo soporte $?^{2}$ y 2 ) ¿ha tenido lugar una recategorización de este verbo, ${ }^{3}$ con lo cual hacer habría adquirido un nuevo significado?

El segundo aspecto que suscita nuestro interés, en el marco de la interrelación entre léxico y sintaxis, es el análisis de algunas combinaciones de ciertas clases aspectuales en español, en concreto de los verbos de estado y de logro, que, en principio, presentaban constricciones sintáctico-semánticas al

2. Para el concepto de gramaticalización ver el libro editado por Costa.

3. La recategorización implica que una unidad perteneciente a una categoría pasa a ser interpretada como otra al pasar a formar parte también, en determinados enunciados, de una nueva categoría, lo que supone la consideración de una polisemia léxica en el proceso y posterior fijación de la recategorización. 
respecto. Es sabido que la clasificación tradicional, desde Vendler (143-60), entre verbos de estados, actividades, efectuaciones y logros, aplicada al español, en comparación con las lenguas eslavas, por ejemplo -de mayor riqueza morfológica en cuanto a la manifestación de la aspectualidad-, y los estudios sobre ciertas pruebas de comportamiento sintáctico-semántico de estos verbos, generan muchas dudas en relación con preguntas como: 1) ¿por qué en español muchos verbos de estado y de logro aceptan construcciones progresivas? (son los casos de expresiones con verbos de logro, por ejemplo, como está entrando, está llegando a la cima o se está muriendo) o 2) ¿qué indica que los cuantificadores de grado estén condicionados por el aspecto léxico verbal y que algunos verbos de estado y logro puedan aceptarlos también en español? (son los casos, también con verbos de logro, de expresiones como está completamente muerto, ba identificado exactamente al asesino o ba descubierto totalmente la verdad).

\section{LA POLISEMIA LÉXICA: BALANCE DE RESULTADOS Y PROBLEMÁTICA} VIGENTE

En nuestra tesis doctoral (Muñoz Núñez 1996) y posterior libro (Muñoz Núñez 1999) nos planteábamos una serie de objetivos, ya enunciados de la Introducción, que podemos retomar en forma de dos cuestiones a las que en su momento dimos -creemos- cumplida respuesta. No obstante, no obviaremos algunos aspectos que siguen siendo problemáticos en el análisis de este fenómeno y, por tanto, siguen constituyendo un campo de análisis abierto, dada la propia naturaleza del significado léxico. Las cuestiones que queremos responder pueden formularse como sigue:

1) ¿qué terminología parecería la más adecuada para referirnos a la vinculación entre un, aparentemente, significante único -en realidad, expresión fónica- $\mathrm{y}$ sus varios significados?, y

2) si bien llegamos a establecer una serie de criterios para distinguir entre signos o invariantes distintos y un mismo signo con diferentes variantes, ¿qué proyección tiene la delimitación de estos dos conceptos más allá del estructuralismo funcional europeo?

2.1 Sobre la primera pregunta, es necesario aclarar que siguen existiendo en la actualidad manuales y libros especializados sobre el tema que establecen la distinción entre polisemia y homonimia. En Muñoz Núñez (1999) partíamos 
de la base de que el estudio que realizaríamos sería sincrónico, lo que implicaba una consecuencia aceptable: fuera cual fuera el término que debíamos adoptar, la estructura sincrónica que se nos presentaba era la de una única expresión fónica, que no significante, ${ }^{4}$ con varios significados o variantes de un significado (en el apartado siguiente nos centraremos en esta cuestión), sin necesidad de cuestionar si a tal expresión fónica se había llegado por la convergencia fonética de dos étimos o por la divergencia semántica de uno solo. Pero, en concreto, nos ratificamos en el hecho de llamar preferentemente a este fenómeno léxico polisemia, como se desprende del título de nuestro libro, esta vez atendiendo a que este término deriva de las palabras griegas polys "numeroso" y seméion "significación", porque en este caso, lo que está en juego es solo un nombre y no un determinado resultado. Además, se trata de denominar a un fenómeno meramente formal, que aparece reflejado en la mayoría de las entradas de un diccionario. Así concluimos en su momento en nuestro libro La polisemia léxica:

Desde el punto de vista sincrónico, en cambio, polisemia y homonimia constituyen, como formulaciones técnicas, pese a aquellos que, situados en esta misma perspectiva, intentan discernir entre uno y otro procesos sobre todo con el establecimiento de algún tipo de relación sémica (por lo general, de carácter subjetivo, asociativo o psicológico) entre sus significados, el mismo fenómeno, pues, desde este punto de vista, es del todo indiferente la distinta procedencia etimológica o no de las palabras homonímicas o polisémicas. Sincrónicamente, en un sistema lingüístico concebido como conjunto de elementos funcionales, sólo debemos considerar si los varios contenidos asociados a una misma expresión fonemática... son variantes o invariantes de contenido, y, en este último caso, cómo se manifiestan esas unidades funcionales distintas. (Muñoz Núñez 1999, 311)

4. En este sentido, ya Gutiérrez Ordóñez (45) advertía que, en general, se ha partido de dos hipótesis implícitas respecto al significante: que su naturaleza es homogénea y que su sustancia es fónica, cuando, en realidad, como ya señaló anteriormente Trujillo en su denominada teoría de la extensión del significante (60), "los significantes no son aquí meras secuencias fónicas -es decir, del llamado "plano de la expresión"- sino hechos sintáctico-semánticos que asumen la función distintiva de la misma manera que podrían hacerlo dos secuencias fónicas diferentes". Para una visión del concepto de significante en el funcionalismo semántico, ver también Casas Gómez (2008, 283-306). 
2.2 Con esta cita abordamos lo que para nosotros constituyó el verdadero entramado que encierran las palabras polisémicas: la distinción, bajo una misma expresión fónica, que no significante, entre invariantes o signos distintos y variantes de un mismo signo. Por eso mismo hablamos de palabras polisémicas y no de signos polisémicos, porque las palabras polisémicas pueden contener, bajo la misma expresión fónica, varios signos.

Para distinguir entre signos distintos y variantes de un mismo signo, o entre invariantes y variantes de contenido, ya se habían analizado, antes del llamado estructuralismo funcional europeo, una serie de factores que atendían al distinto comportamiento morfológico y sintáctico, sobre todo, de tales signos -análisis que podemos encontrar en los trabajos de autores como Ullmann, Ducháček, adscritos a la denominada semántica preestructural, siguiendo la denominación que Casas Gómez (1998, 159-84) establece para las diferentes etapas historiográficas de la Semántica-. Pero fueron, sobre todo, ya en el ámbito de la semántica estructural en sentido amplio, autores como Palmer, Schogt, Paul, Lyons, por una parte, y Trujillo y Gutiérrez Ordóñez, ${ }^{5}$ en el ámbito hispánico, por otra, los que fijaron más exhaustivamente los criterios morfológicos, léxicos y sintácticos de distinción entre signos distintos y variantes de un mismo signo. Para sintetizar un análisis que abarca algo más de dos décadas (aunque básicamente desde los años 70 a 80) nos fijaremos en los ejemplos de dos adjetivos del español, seco y agudo, que representan, cada uno, diferentes signos.

Así, la expresión fónica de seco contiene los signos seco1/mojado, seco2/ graso, seco3/verde, seco4/gordo, seco5/agradable, seco6/dulce, seco7/búmedo, y la expresión fónica de agudo contiene, al menos, los signos agudo1/afilado, agudo2/ inteligente, agudo3/intenso. Por lo que podemos apreciar, en el caso de seco cada uno de sus significados se oponen a antónimos diferentes, y en el de agudo a "sinónimos" también diferentes (sin entrar en el problema de la existencia o no de sinónimos absolutos). ${ }^{6} \mathrm{Si}$ esta misma prueba de búsqueda de antónimos o sinónimos la hiciéramos, por ejemplo, con el adjetivo viejo, en jersey viejo, hombre viejo o caballo viejo, estamos casi convencidos de que los resultados serían menos homogéneos, al menos, creemos que tendríamos que pensar más sobre las posibles correspondencias de viejo con antónimos y "sinónimos",

5. Autores cuyos trabajos fueron ampliamente citados y analizados en nuestra tesis doctoral (Muñoz Núñez 1996) y libro (Muñoz Núñez 1999).

6. Ver, para el fenómeno de la sinonimia, y, en concreto, para el ejemplo citado, el trabajo de Casas Gómez (1999, 53, n. 32). 
porque este adjetivo nos sugiere correspondencias antonímicas y "sinonímicas" más allá de lo que muchos llamaríamos en algún momento sistema de la lengua.

El objetivo de deslindar entre invariantes y variantes de contenido se convirtió en algo inabarcable cuando nos sumergimos simplemente en el léxico del español de Uruguay. La delimitación entre invariantes y variantes de contenido ya no fue el objetivo central y dejó paso a otro en forma de pregunta: ¿tiene sentido distinguir entre invariantes y variantes de contenido dentro de un sistema lingüístico si las modalidades, en este caso, diatópicas, son simplemente distintas y, en definitiva, sistema o lengua y habla son constructos del lingüista y no de los hablantes?

Además, en relación con la percepción de los hablantes al respecto, ya en un artículo posterior a nuestro libro, sobre oposiciones y análisis del contenido léxico (Muñoz Núñez 2002, 77-94), reformulamos la idea, defendida, entre otros, por Mahmoudian (26-27), que hacía referencia a la relatividad de la pertinencia, o del carácter discreto o diferencial de las unidades lingüísticas, y, por tanto, aludía a la también relatividad de la estructura, idea interesante pero que, en nuestra opinión, conducía a la confusión entre constante y discreto, por una parte, y variable y no discreto, por otra. Desde nuestro punto de vista, constante y variable hacen referencia a lo consensuado o no dentro de un sistema lingüístico (insistimos, si se puede mantener este constructo teórico); en cambio, discreto o diferencial alude al comportamiento de las unidades, y este carácter discreto o diferencial se mantiene tanto en lo constante como en lo variable. Así, no creemos que un hablante uruguayo repare en que su acepción de pararse 'ponerse de pie', además de 'detenerse' (véase el diccionario 1000 palabras del español del Uruguay, 1998, 107), no es la usual entre los hablantes españoles, sino que simplemente establece una oposición entre pararse y sentarse y pararse y seguir.

En definitiva, fue precisamente la imposibilidad de abarcar los componentes diastrático, diafásico y, ante todo, diatópico de las lenguas lo que nos hizo dudar sobre la fiabilidad de trazar límites precisos entre invariantes y variantes de contenido en muchos casos, o, más bien, lo que nos hizo percibir que esta podría convertirse en una tarea tan ardua como irrelevante, a menos que nos empeñemos en seguir manteniendo igualmente una estricta diferencia entre arquitectura y estructura de la lengua, tal como fue formulada por Coseriu (118-23). De esta manera, el objetivo de elaborar un diccionario funcional quedó solo como un esbozo planteado en este marco. 


\section{ALGUNOS ASPECTOS DE LA RELACIÓN ENTRE LÉXICO Y SINTAXIS}

Ha sido en los últimos años, indagando en las posibilidades que ofrece el análisis del léxico atendiendo a su proyección en la sintaxis, cuando hemos constatado la importancia de la interrelación entre el léxico y la sintaxis para recabar datos más fiables, si cabe, sobre la información semántica contenida en las unidades léxicas, y ello sin importar si estamos ante invariantes o variantes de contenido, sino atendiendo a la consideración misma de que, involucrada una polisemia léxica, nos acercamos a una mejor comprensión de lo que sucede, sobre todo, en las locuciones que vamos a analizar y en la aceptabilidad de ciertas otras expresiones con verbos de estado y de logro. Además, plantearemos si las unidades léxicas implicadas en todos estos casos se han recategorizado (podría ser el caso del verbo hacer en la expresión hacer el payaso o el caso del verbo morir en se está muriendo), lo que constituye una prueba más del fenómeno polisémico.

\subsection{Colocaciones léxicas vs. locuciones}

3.1.1 En el marco de la delimitación entre restricciones léxicas y colocaciones, ya en un trabajo sobre los criterios de diferenciación entre ambos conceptos (Muñoz Núñez 2007, 177-98) argumentamos a favor de la distinción. Además, dejamos constancia del origen del término y del concepto de colocación para hacer referencia a unidades que adquieren especial relevancia como elementos caracterizadores de un "registro" determinado en los estudios sobre los lenguajes de especialidad, como bien apuntó Corpas Pastor (46). Es lo que sucede en los casos de las colocaciones vaca torionda, cerda verrionda u oveja morionda -citados por García Page (222), en alusión a G. Salvador, aunque considerándolos como ejemplos de "expresiones fijas" -, correspondientes al ámbito de la ganadería.

Aunque el objetivo de este apartado es el análisis de ciertas construcciones con el verbo hacer, convertido en verbo soporte (en comparación con otras, más analizadas, con el verbo dar), nos resulta necesario retomar las características que en su momento expusimos, y que seguimos pensando que diferencian las colocaciones de las restricciones léxicas, porque, cuando interviene, en concreto, un verbo soporte en ciertas construcciones, en su caracterización adquiere también fuerza el concepto de locución. Así, las colocaciones (Muñoz Núñez 2007, 193-94) se caracterizan porque: 
1. no son combinaciones idiomáticas, pero sí frecuentes y preferentes, como en fruncir el ceño, guiñar un ojo o escanciar la sidra, lo cual no creemos que deba identificarse con la idea de arbitrariedad en la unión de colocativo y base, ya que, como señala Bosque (2001a, 30-31), esa preferencia puede depender de la existencia de "lugares comunes" o de representantes prototípicos;

2. la relación entre sus miembros puede ser tanto exclusiva de esos elementos, como sucede en muchas colocaciones adscritas a ámbitos especializados (dictar sentencia, proclamar autos o ratificar convenios) o no especializados (caldearse el ambiente, calentarse los ánimos o encender pasiones), o bien la clase con la que se combina uno de ellos es enormemente restringida (ensortijarse el pelo, escanciar la sidra o levar anclas); es decir, nunca se habló de una biunivocidad necesaria, más allá de lo que ocurre en cierto tipo de solidaridades léxicas, concepto formulado por Coseriu (143-61), en concreto en la denominada afinidad, que se da en casos como ladrar un perro, arrullar una paloma o rugir un león;

3. en ellas no tiene gran relevancia la selección argumental, más bien, es difícil determinar la direccionalidad de la selección. De esta manera, cabría preguntarse quién es el colocativo y quién la base en, por ejemplo, zarpar un barco, arriar la vela o izar la bandera, $\mathrm{y}$

4. ambos elementos de la colocación son autosemánticos, idea que amplía la de muchas opiniones vertidas a propósito de que en las colocaciones hay al menos una unidad autosemántica, que coincide con la base (remitimos al ejemplo de Haussmann (192) de célibataire endurci, base y colocativo respectivamente, sobre el que este autor dice que la base completa la definición del colocativo). Sin embargo, en ejemplos como caldearse el ambiente, calentarse los ánimos o encender pasiones los colocativos (los verbos) presentan una acepción muy específica en relación con su base. Además, en estos tres casos esas acepciones son figuradas, aunque este hecho no convierta a tales combinaciones en idiomáticas.

3.1.2 En relación con el hecho de que en muchos casos el colocativo tiene un uso figurado, algunos autores han presentado esta circunstancia como muestra de la difícil delimitación entre colocaciones y locuciones y también como prueba del paso de unas a otras. Ya en nuestro artículo sobre el uso figurado en unidades plurilexemáticas como las colocaciones y los compuestos sintagmáticos (Muñoz Núñez 2010a, 253-70), expresamos nuestra opinión sobre el papel de los usos 
figurados en la caracterización de estas combinaciones y concluimos que los diferentes grados de transparencia u opacidad no inciden en la delimitación entre estos dos tipos de unidades (ver de nuevo Muñoz Núñez 267), pero ¿y en la delimitación de locuciones?

Compárense todos los casos citados de colocaciones en el apartado 3.1.1 con estos otros en los que interviene el verbo dar, que, en combinación con los sustantivos correspondientes, se ha gramaticalizado: dar alas, dar carpetazo, dar fe, dar margen, dar paso. Hemos seleccionado estos cinco ejemplos de un total de 97 combinaciones de dar + sustantivo, analizadas en la Memoria de Licenciatura -inédita- de Polakof, que dirigimos. La autora comprobó la presencia o no de las 97 combinaciones en el Diccionario combinatorio del español contemporáneo (REDES), dirigido por Bosque, en el Diccionario fraseológico del español moderno (DFEM), de Varela y Kubarth, y en el Diccionario de locuciones verbales para la enseñanza del español (DLVEE), de Penadés Martínez, y obtuvo, comparando la información que aparece en los tres diccionarios, los siguientes resultados:

\begin{tabular}{lcc} 
CRUCES & $\mathrm{N}=97$ & PORCENTAE \\
\hline a) Restricción-Locución & 39 & 40,2 \\
\hline b) Colocación-Locución & 49 & 50,5 \\
\hline c) Restricción-Colocación Locución & 9 & 9,3 \\
\hline
\end{tabular}

De estos resultados se desprende que 49 casos aparecían como colocaciones y locuciones en los diccionarios correspondientes, 39 casos como restricciones y locuciones, y 9 casos como restricciones, colocaciones y locuciones.

Volviendo a los ejemplos que hemos seleccionado con el verbo dar, para su posterior comparación con otros ejemplos con el verbo hacer, en los que ambos actúan como verbos soporte, es decir, atendiendo a los casos dar alas, dar carpetazo, dar fe, dar margen, dar paso, constatamos que tales ejemplos aparecen en REDES, pero también en el DFEM, y solo tres de ellos (dar alas, dar carpetazo y dar paso) en el DLVEE. La autora de este último diccionario justificaba en su momento que las construcciones en las que aparece dar como verbo soporte son colocaciones porque las colocaciones contienen palabras autosemánticas y porque "de ser locuciones, su definición debería hacerse sin mencionar el sustantivo contenido en la hipotética locución, lo que no es el caso en las definiciones del propio DFEM" (Penadés Martínez 2001, 62). Sin embargo, las acepciones de alas, carpetazo, fe, margen y paso que se utilizan en las correspon- 
dientes definiciones de estas locuciones, así entendidas por Varela y Kubarth, no son las que corresponden a los sustantivos independientes, sino otras figuradas. No obstante, parece que la polémica está servida en cuanto a que estas unidades sean colocaciones o locuciones.

Analicemos ahora lo que sucede con las combinaciones que hemos elegido en las que es ahora hacer-menos estudiado que dar-el que interviene como verbo soporte: hacer cuentas, hacer el payaso, hacer una barriga, bacer una montaña de un grano de arena y hacer un siete. Esta vez ninguna de estas combinaciones aparece en REDES; con excepción de hacer una montaña de un grano de arena, las demás aparecen en el DFEM, y, en cuanto al DLVEE, en él aparecen sólo hacer el indio (no el payaso), hacer una barriga y bacer una montaña de un grano de arena.

Aunque la experiencia de campo nos indica que es muy difícil encontrar un consenso respecto a las combinaciones en las que verbos como dar y hacer se han gramaticalizado, partimos en este trabajo de la siguiente idea, reforzada fundamentalmente por nuestros estudios de las colocaciones: toda construcción que contiene un verbo soporte es una locución. Pasamos a argumentarla consecuentemente con las características de las colocaciones que expusimos. Retomamos, sobre todo, por una parte, la no idiomaticidad de las colocaciones, o su composicionalidad, que siempre se mantiene en mayor o menor medida, a pesar de los usos figurados que pueda tener el colocativo, y, por otra, la idea de que en las colocaciones ambas unidades son autosemánticas. Por el contrario, las locuciones que contienen un verbo soporte, como dar o hacer, casi siempre son idiomáticas. En los casos del verbo hacer en combinación con distintos sustantivos, al haber perdido este verbo su semantismo, adoptando el particular uso figurado de convertirse en verbo soporte, los correspondientes sustantivos con los que se combina no pueden leerse tampoco composicionalmente; así, nadie hace, por ejemplo, una barriga como hace un pastel, ni tampoco como bace un siete (pero, de nuevo, puede que la polémica esté servida).

\subsection{Los casos particulares de los verbos de estado y de logro}

3.2.1 Según hemos comentado en la introducción, y ahora en mayor medida en el marco de la relación entre el léxico y la sintaxis, ${ }^{7}$ nuestras investigacio-

7. Y decimos en mayor medida porque tanto en las colocaciones verbo + sustantivo como en las locuciones con los verbos dar y hacer que hemos analizado nos encontramos ante verdaderos actos de habla, es decir, enunciados completos. 
nes también se centran en ciertas constricciones sintáctico-semánticas de la aspectualidad en español, constricciones que atañen a los verbos de estado y de logro y en lo que implica su particular comportamiento sintáctico-semántico, siempre teniendo como hilo conductor el fenómeno de la polisemia léxica, y de nuevo para comprobar si estamos o no ante casos de recategorizaciones de unidades léxicas. Ya Morimoto y de Miguel (2977-3060), entre otros autores, habían señalado que ni los verbos de estado ni los de logro aceptan normalmente construcciones progresivas, como se puede comprobar en los casos inaceptables de *La familia está poseyendo la empresa -construcción progresiva con un verbo de estado- y * Me estoy encontrando con María -construcción progresiva con un verbo de logro- (ejemplos extraídos de Morimoto 20 y 22). A esta limitación en construcciones progresivas añadiremos la de que ambos tipos de verbos tampoco aceptan a veces cuantificadores de grado, como también se puede comprobar en los ejemplos inaceptables de *Ella cree mucho que tiene un virus -interviniendo aquí un verbo de estado- ${ }^{*}$ Ella muere mucho -donde morir es un verbo de logro- (ejemplos extraídos de Vigueras Ávila, estudio, hasta donde nos consta, inédito).

3.2.2 De todas formas, en lo que se refiere a la no aceptación de cuantificadores de grado por verbos de estado y de logro, debemos hacer algunas puntualizaciones, ya que hemos indicado que esto sucede a veces, pero no constituye una generalidad. Ya en nuestro artículo sobre determinados aspectos de la cuantificación de grado (Muñoz Núñez 2010b, 461-82), habíamos hecho una incursión en diferentes manifestaciones de la aspectualidad (Aktionsart y no aspecto flexivo) en español. De ese artículo nos interesa destacar ahora nuestras reflexiones sobre la presencia o cancelación de un cuantificador de grado en relación con la aspectualidad verbal (y especificamos lo de verbal porque la aspectualidad en español, al menos, es una propiedad transcategorial). En concreto, ¿̇por qué se aceptan enunciados como se parece mucho a su madre y no *ree mucho que tiene un virus (con verbos de estado)? y ¿por qué se acepta, por ejemplo, se despierta mucho cuando tiene pesadillas y no *muere mucho (con verbos de logro)?

Es necesario aclarar que ya entonces abordábamos, entre otras cuestiones, dos puntos de vista en relación con la denominada "cuantificación de grado verbal": 1) el de los que se preguntaban sobre qué lecturas tenía un enunciado cuando aceptaba un cuantificador de grado (postura representada, entre otros, por Vigueras Ávila) y 2) el de los que se preguntaban sobre la verdadera incidencia de un cuantificador de grado cuando en la construc- 
ción participa un verbo, y no un adjetivo o, incluso, un sustantivo (postura representada, entre otros, por Bosque 2001b, 39-79). Este último punto de vista necesitaría una larga argumentación, más allá de las pretensiones de este trabajo, por lo que remitimos para ella a nuestro estudio citado.

Partimos, pues, de la postura de los autores que han analizado las lecturas que tiene un enunciado cuando acepta un cuantificador de grado o lo cancela, siguiendo el trabajo de Vigueras Ávila sobre aspecto verbal y cuantificación adverbial gradual, para interpretar por qué ocurre una u otra circunstancia en las siguientes expresiones, en primer lugar, con verbos de estado:

-Sara se parece mucho a su abuela.

-Ella cree mucho en Dios.

-Ella cree mucho que tiene un virus.

$-{ }^{*}$ Los demonios existen mucho.

De los 27 casos analizados por Vigueras Ávila, 15 aceptan el cuantificador de grado mucho, porque cuando la expresión lo acepta es porque se expande un "dominio mental" (en palabras de la autora), dominio mental que no se puede expandir en los casos de creer, en la acepción de 'tener la certeza' ni de existir, porque algo existe o no. Pensamos, además, que en los casos en que se expande un "dominio mental" el comportamiento de tales verbos es parecido al de los adjetivos calificativos que admiten gradación; en cambio, cuando no hay tal expansión, la propiedad con la que nos enfrentamos es absoluta (creer, 'tener la certeza' y existir serían como los adjetivos calificativos absolutos cuadrado o redondo).

Ahora analicemos las siguientes expresiones con verbos de logro:

-Los niños se caen mucho cuando aprenden a caminar.

-Se despierta mucho cuando tiene pesadillas.

-*Ella muere mucho.

En el caso de los verbos de logro, de los 13 casos analizados por Vigueras Ávila, 6 aceptaban el cuantificador de grado mucho, porque al ser el logro puntual, la única lectura que cabe es la iteración del dominio. Pero esta iteración es imposible en morir, dado el semantismo de este verbo.

A las anteriores expresiones con verbos de logro añadimos estos otros ejemplos: 
-Está completamente muerto.

-Ha identificado exactamente al asesino.

- Ha descubierto totalmente la verdad.

Nadie *muere mucho, tampoco *se identifica mucho al asesino, ni * se descubre mucho la verdad. Ahora bien, estos actos de habla sí tienen sentido si se utiliza el cuantificador de grado elativo, es decir, el que está situado en el grado máximo de la escala, nunca en algún lugar intermedio, y es así porque con ellos -completamente, exactamente y totalmente- se da cuenta de que los eventos de morir, identificar y descubrir, sin duda, han tenido lugar.

3.2.3 Pero, como también adelantábamos en la Introducción, se ha dicho que los verbos de estado y de logro tampoco aceptan, en general, construcciones progresivas. Sin embargo, pueden resultar aceptables ejemplos como estoy conociendo a mucha gente, está creyendo cada vez más en Dios (con verbos de estado), está saliendo de Madrid, se está muriendo y está llegando a la cima (con verbos de logro), esta última expresión muy citada en los trabajos sobre aspectualidad en español y para la que unánimemente se da una interpretación ingresiva = está a punto de llegar a la cima.

Como para muchas expresiones que hemos analizado se tienen opiniones diversas y, puesto que de algunas de ellas se dice que son inaceptables, hemos realizado un test a un total de 20 hablantes, no solo alumnos del Grado en Linguiística y Lenguas Aplicadas de la Universidad de Cádiz, sino también a otros hablantes con edades superiores a los 23 años con estudios universitarios, test en el que se les preguntaba sobre la aceptabilidad o no de una serie de construcciones progresivas.

En concreto, y atendiendo a los verbos de estado, las expresiones eran:

- Está confiando cada vez más en él.

-Me está queriendo cada vez más.

-Está aceptando mi postura.

Once hablantes han considerado estas expresiones aceptables; cinco, inaceptables y cuatro hablantes, dudosa.

En cuanto a las construcciones progresivas con verbos de logro, las expresiones sobre las que se les preguntó -con resultados más dispares- eran: 
- Juan está llegando a Madrid (17 hablantes, aceptable; uno, inaceptable y dos, dudosa).

-Se está muriendo (14 hablantes, aceptable; tres, inaceptable y tres, dudosa).

-Se está despertando (12 hablantes, aceptable; seis, inaceptable y dos, dudosa).

Como comprobamos, en todos los casos de construcciones progresivas, tanto con verbos de estado como de logro, predomina la aceptabilidad. También constatamos que la aceptabilidad en estos casos proviene del hecho de que estas dos clases aspectuales han dejado de ser exactamente tales para convertirse en clases con aspectualidad ingresiva, es decir, de comienzo de acción, aunque más claramente en los verbos de logro que de estado, más próximos estos últimos, en algunos casos, a una interpretación progresiva (me está queriendo cada vez más, por ejemplo).

\section{CONCLUSIONES}

A lo largo de este trabajo hemos realizado una revisión de los objetivos alcanzados en nuestra tesis doctoral y, al mismo tiempo, planteado que la dificultad para distinguir entre variantes e invariantes de contenido solo tiene relevancia en el marco de los constructos teóricos de la semántica estructural de corte europeo -en especial, de la semántica coseriana-.

Una vez asimilada la percepción de que es posible un estudio más exhaustivo del léxico a partir de su relación con la sintaxis, hemos abordado, en una segunda parte, en primer lugar, los límites entre colocaciones y locuciones, para concluir que muchos verbos soporte generan, por las consideraciones realizadas en los apartados 3.1.1 y 3.1.2, una locución, como sucede en hacer el payaso, hacer una montaña de un grano de arena, etc.

En segundo lugar, de nuestro estudio sobre algunas expresiones, con verbos de estado y de logro, que admiten tanto cuantificadores de grado como construcciones progresivas, extraemos un espectro algo más amplio de posibilidades. Así, teniendo en cuenta las dos pruebas que hemos aplicado a los verbos de estado y de logro, podemos concluir lo siguiente:

1. En relación con los verbos de estado, cuando aceptan cuantificadores de grado, están expandiendo un "dominio mental” y, por tanto, se están 
comportando como verbos en cuyo semantismo tiene mucha presencia la idea de cualidad; además, parecería que siguen conservando su estatus de situaciones de no cambio; en construcciones progresivas, en cambio, se muestran a veces próximos a la lectura ingresiva (está aceptando mi postura), aunque también progresiva (me está queriendo cada vez más).

2. En lo que se refiere a los verbos de logro que aceptan cuantificadores de grado, estos verbos pasan a tener una interpretación iterativa (se despierta mucho, los niños se caen mucho); y cuando aceptan construcciones progresivas su interpretación pasa a ser ingresiva, es decir, de comienzo de acción (está saliendo, está llegando, se está muriendo = a punto de...). En este segundo tipo de verbos -los de logro-, sí parecería clara su recategorización en dos subclases aspectuales, como son la iterativa y la ingresiva, lectura esta última (tampoco la progresiva) que no está nada clara cuando se trata de verbos de estado que aceptan construcciones progresivas, aunque se haya hablado de esta lectura en ejemplos como Estoy conociendo a mucha gente (ver Morimoto 20).

De lo anteriormente expuesto resulta indiscutible que cuando se habla de temas como construcciones con verbos soporte, colocaciones, aspectualidad en sus diferentes manifestaciones en español, desde la unidad verbal hasta la naturaleza composicional de la aspectualidad, siempre subyace, al menos en estos casos, la polisemia léxica. Esto indica que estamos ante un fenómeno vigente, vivo, necesario en el uso de las lenguas, que sigue incidiendo bajo distintas manifestaciones en muchas de las operaciones que realizamos cuando hablamos, como es el caso de los enunciados que hemos analizado a lo largo de este trabajo, y, en definitiva, indica la continua posibilidad que se nos ofrece en las lenguas de recategorizar un gran número de unidades léxicas.

\section{OBRAS CITADAS}

1000 palabras del español del Uruguay. Montevideo: Academia Nacional de Letras, 1998.

Bosque, Ignacio. “Sobre el concepto de 'colocación' y sus límites”. Lingüística Española Actual 23.1 (2001a): 9-40.

Bosque, Ignacio. "Sobre la gramática de la gradación”. Sociedad Chilena de Lingüistica: un aniversario especial. Ed. Alba Valencia. Santiago de Chile: LOM Ediciones, 2001b. 39-79. 
Bosque, Ignacio. Redes: diccionario combinatorio del español contemporáneo. Madrid: Editorial SM, 2004.

Casas Gómez, Miguel. "Del historicismo al preestructuralismo semánticos". Estudios de lingüistica general: actas del II Simposio de Historiografía Lingüística (Córdoba, 18-20 de marzo de 1997). Eds. Feliciano Delgado León, $\mathrm{M}^{\mathrm{a}}$ Luisa Calero Vaquera y Francisco Osuna García. Córdoba: Universidad de Córdoba. 1998. 159-84.

Casas Gómez, Miguel. "El concepto de significante en el funcionalismo semántico". Romanische Forschungen 120.3 (2008): 283-306.

Casas Gómez, Miguel, y M ${ }^{\mathrm{a}}$ Dolores Muñoz Núñez. "La polisemia y la homonimia en el marco de las relaciones léxicas". Estudios de lexicología y metalexicografía del español actual. Ed. Gerd Wotjak. 47. Lexicographica Series Maior. Tübingen: Niemeyer, 1992. 134-58.

Corpas Pastor, Gloria. “Apuntes para el estudio de la colocación”. Lingüística Española Actual 23.1 (2001): 41-56.

Coseriu, Eugenio. "Introducción al estudio estructural del léxico". Principios de semántica estructural. Madrid: Gredos, 1977. 87-142.

Coseriu, Eugenio. "Las solidaridades léxicas". Principios de semántica estructural. Madrid: Gredos, 1977. 143-61.

Costa, Sylvia. Estudios de Lingüística Hispánica II. Gramaticalización y lexicalización. Ed. Sylvia Costa. Montevideo: Universidad de la República, 2011.

De Miguel, Elena. "El aspecto léxico". Gramática descriptiva de la lengua española. Dirs. Ignacio Bosque y Violeta Demonte. Madrid: Espasa, 1999. 2977-3060.

García-Page, Mario. "Sobre implicaciones lingüísticas: solidaridad léxica y expresión fija”. Estudios humanisticos: filología 12 (1990): 215-28.

Gutiérrez Ordóñez, Salvador. Introducción a la semántica funcional. Madrid: Síntesis, 1989.

Haussmann, Franz Josef. "Un dictionnaire des collocations est-il possible? Travaux de Linguistique et de Littterature 17.1 (1979): 187-95.

Mahmoudian, Morteza. "Structure linguistique: problèmes de la constance et des variations". La Linguistique 16.1 (1980): 5-36.

Morimoto, Yuko. El aspecto léxico: delimitación. Madrid: Arco/Libros, 1998.

Muñoz Núñez, $M^{\mathrm{a}}$ Dolores. La polisemia léxica: propuesta de delimitación e identificación funcional de los significados de sustantivos polisémicos. Tesis doctoral microfilmada. Cádiz: Universidad de Cádiz, 1996.

Muñoz Núñez, Mª Dolores. La polisemia léxica. Cádiz: Universidad de Cádiz, 1999. 
Muñoz Núñez, $M^{a}$ Dolores. "Oppositions and analysis of lexical content". Quaderni di Semantica, 23.1 (2002): 77-94.

Muñoz Núñez, $M^{a}$ Dolores. "Colocaciones y restricciones léxicas: criterios de diferenciación". Estudios de Lingüística Hispánica. Eds. Virginia Bertolotti, Serrana Caviglia, Sylvia Costa, Mariela Grassi, Marisa Malcuori y Mª Dolores Muñoz Núñez. Cádiz: Universidad de Cádiz, 2007. 177-98.

Muñoz Núñez, $M^{a}$ Dolores. "El uso figurado en algunos casos de unidades plurilexemáticas: colocaciones y compuestos sintagmáticos”. Estudios de Linguiistica de la Universidad de Alicante 24 (2010a): 253-70.

Muñoz Núñez, $M^{a}$ Dolores. "Algunos aspectos de la cuantificación de grado: con especial atención a la llamada 'cuantificación de grado verbal"”. Nueva Revista de Filología Hispánica 58.2 (2010b): 461-82.

Penadés Martínez, Inmaculada. “¿Colocaciones o locuciones verbales?”. Lingiǘstica Española Actual 23.1 (2001): 57-88.

Penadés Martínez, Inmaculada. Diccionario de locuciones verbales para la enseñanza del español. Madrid: Arco/Libros, 2002.

Polakof, Ana Clara. Colocaciones, restricciones léxicas y locuciones: construcciones con el verbo dar. Memoria de Licenciatura inédita. Montevideo: Universidad de la República, 2007.

Trujillo, Ramón. Elementos de semántica lingüística. Madrid: Cátedra, 1976.

Varela, Fernando, y Hugo Kubarth. Diccionario fraseológico del español moderno. Madrid: Gredos, 1994.

Vendler, Zeno. "Verbs and Times". The Philosophical Review 66 (1957): 143-60.

Vigueras Ávila, Alejandra. "Aspecto verbal y cuantificación adverbial gradual”. Comunicación presentada en el VI Congreso de Lingüística Hispánica (Leipzig, 7-12 de octubre de 2003). Texto inédito. 